\title{
Penyuluhan dan Pelatihan Pajak Usaha Mikro, Kecil, dan Menengah (UMKM) pada Kelompok Karang Taruna di Kelurahan Balekambang Jakarta Timur
}

\author{
Siti Juriah, Rudeva Juniawaty \\ Universitas Indraprasta PGRI
}

\begin{abstract}
Abstrak
Pelaksanaan abdimas ini memiliki tujuan untuk membantu pemerintah dalam meningkatkan penerimaan pajak dari sektor UMKM. UMKM merupakan usaha yang tetap berdiri kokoh pada masa krisis 1997-1998, hal ini dikarenakan mayoritas usaha berskala kecil yang tidak terlalu tergantung pada modal besar atau pinjaman dari luar dalam mata uang asing. Sehingga, ketika ada fluktuasi nilai tukar, perusahaan berskala besar yang secara umum selalu berurusan dengan mata uang asing adalah yang paling berpotensi mengalami imbas krisis. 99\% pelaku usaha di Indonesia merupakan pelaku UMKM, namun dari data jumlah wajib pajak yang tercatat sebanyak 42 juta wajib pajak, maka masih terdapat 40,2 juta wajib pajak yang belum membayarkan pajak. Salah satu faktor yang memengaruhi wajib pajak orang pribadi dalam membayarkan pajak antara lain adalah pengetahuan dan pemahaman wajib pajak tentang peraturan perpajakan. Berdasarkan hal tersebut maka tim terpikir untuk membuat penyuluhan dan pelatihan mengenai perpajakan UMKM. Mitra kami adalah Karang Taruna Kelurahan Balekambang yang memiliki unit bisnis baru. Kami melihat mitra kami merupakan pihak yang potensial untuk diberikan penyuluhan dan pelatihan perpajakan yang terkait dengan bisnis mereka.
\end{abstract}

Kata Kunci: karang taruna, UMKM, PP 23 Tahun 2018

\section{Counseling and Training on Taxation for Micro, Small, and Medium Enterprise (MSME) at Karang Taruna Balekambang Village, East Jakarta}

\begin{abstract}
The purpose of this activity is to assist the government in increasing tax revenue from the MSME sector. MSME is a business that has remained strong during the 1997-1998 crisis, this is because the majority of small-scale businesses are not too dependent on large capital or loans from outside in foreign currency. Thus, when there are fluctuations in exchange rates, large-scale companies that generally always deal with foreign currencies are the ones that have the most potential to experience the impact of the crisis. 99\% of business actors in Indonesia are MSME players, but from the data on the number of taxpayers that are recorded as many as 42 million taxpayers, there are still 40.2 million taxpayers who have not paid taxes. One of the factors that affect individual taxpayers in paying taxes, among others, is the taxpayer's knowledge and understanding of tax regulations. Based on this, the team thought about providing counseling and training on MSME taxation. Our partner is Karang Taruna Balekambang Village which has a new business unit. We see our partners as potential parties to be provided with education and training on taxation related to their business.
\end{abstract}

Keywords: youth organization, MSME, PP 23/2018

\section{PENDAHULUAN}

Anggaran Pendapatan dan Belanja Negara (APBN) 2020 resmi disahkan pada akhir tahun 2019. Pendapatan negara ditargetkan sebesar Rp 2.233,2 triliun atau naik 0,53\% dari RAPBN 2020 yang sebesar Rp2.221,5 triliun. Perubahan juga terjadi pada pos belanja 
Vol. 1, No. 3,

November

2020

pp. 93-99

e-ISSN:

2722-2004

\section{Title}

Counseling and Training

on Taxation

for Micro,

Small, and

Medium

Enterprise

(MSME) at

Karang

Taruna

Balekambang

Village, East

Jakarta

Author

Siti Juriah, R. Juniawaty

negara, yaitu naik 0,46\% dari APBN 2020 yang sebesar Rp2.528,8 triliun menjadi Rp2.540,4 triliun pada RAPBN 2020 (www.kemenkeu.go.id). Penerimaan pajak 2020 meningkat dari Rp1.643,1 triliun pada 2019 menjadi Rp1.865,7 triliun atau naik sebesar $13,55 \%$. Penerimaan pajak sendiri memiliki porsi $83,54 \%$ dari total APBN 2020.

\section{Pendapatan Negara Tahun} 2020

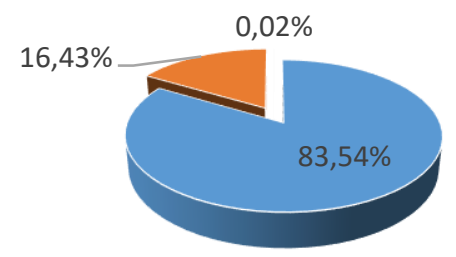

- Penerimaan Pajak (dalam Triliun)

- PNBP (dalam Triliun)

- Hibah (dalam Triliun)

Gambar 1. Pendapatan Negara Tahun 2020

Berdasarkan gambar 1, dapat dilihat bahwa penerimaan pajak memiliki porsi terbesar dalam APBN yaitu sebesar 83,54\%. Dilihat dari pertumbuhannya, penerimaan perpajakan mengalami pertumbuhan rata-rata sebesar $7,3 \%$ per tahun sepanjang 2015-2018. Paling tinggi terjadi pada tahun 2018, yaitu sebesar $13 \%$. Peningkatan target penerimaan perpajakan tidak terlepas dari adanya kenaikan jumlah wajib pajak.

Pada tahun 2019, pemerintah mencatat ada sebanyak 42 juta wajib pajak. Jumlah tersebut naik dari tahun 2018 sebesar 38,7 juta. Dari seluruh Nomor Pokok Wajib Pajak (NPWP) yang tercatat di Direktorat Jenderal Pajak, sebanyak 38,7 juta di antaranya merupakan wajib pajak orang pribadi. Sementara 3,3 juta sisanya adalah wajib pajak badan (korporasi/perusahaan) (www.cnbcindonesia.com).

Berdasarkan data di atas, wajib pajak orang pribadi merupakan komponen terbesar dalam database perpajakan. Hal ini menunjukkan bahwa wajib pajak orang pribadi memiliki potensi besar dalam penerimaan pajak. Pada kisaran 19971998, jumlah pengusaha di Indonesia sebanyak 56.539.560 unit. Dari jumlah tersebut, usaha mikro kecil dan menengah (UMKM) sebanyak 56.534.592 unit atau $99.99 \%$. Sisanya, sekitar $0,01 \%$ atau 4.968 unit adalah usaha besar.

Pada masa krisis 1997-1998, UMKM mampu tetap berdiri kokoh hal ini dikarenakan mayoritas usaha berskala kecil yang tidak terlalu tergantung pada modal besar atau pinjaman dari luar dalam mata uang asing. Sehingga, ketika ada fluktuasi nilai tukar, perusahaan berskala besar yang secara umum selalu berurusan dengan mata uang asing adalah yang paling berpotensi mengalami imbas krisis.

Data Badan Pusat Statistik memperlihatkan, pasca krisis ekonomi tahun 1997-1998 jumlah UMKM tidak berkurang, justru meningkat terus, bahkan mampu menyerap 85 juta hingga 107 juta tenaga kerja sampai tahun 2012. Usaha Mikro, Kecil dan Menengah (UMKM) mempunyai peran penting dan strategis dalam pembangunan ekonomi nasional. Selain berperan dalam pertumbuhan 
ekonomi dan penyerapan tenaga kerja, UMKM juga berperan dalam mendistribusikan hasil-hasil pembangunan.

Walaupun mayoritas pengusaha di Indonesia adalah pelaku UMKM, namun kontribusi pajak dari sektor UMKM masih minim. Hal ini didasarkan pada data Kementerian Keuangan bahwa hingga saat ini, UMKM memegang porsi hingga 65 persen dari sisi jumlah pelaku usaha dalam perekonomian di Indonesia, tapi dari sisi jumlah pembayar pajak yang aktif, baru mencapai 1,8 juta UMKM (www.bisnis.com). Jika dibandingkan dengan data jumlah wajib pajak yang tercatat sebanyak 42 juta wajib pajak, maka masih terdapat 40,2 juta wajib pajak yang belum membayarkan pajak.

Menurut penelitian Damayanti dkk, (2020: 153) faktor-faktor yang memengaruhi wajib pajak orang pribadi dalam membayarkan pajak antara lain adalah pengetahuan dan pemahaman wajib pajak tentang peraturan perpajakan. Dengan rendahnya tingkat pengetahuan wajib pajak tentu berpengaruh terhadap penerimaan pajak. berdasarkan hal tersebut di atas, kami tertarik untuk memberikan penyuluhan tentang pajak, terutama pajak untuk sektor UMKM.

Dengan modal yang didapat dari hadiah hasil lomba-lomba yang diadakan oleh Pemda DKI Jakarta, remaja karang taruna saat ini sedang giat membangun usaha mikro. Dalam proses produksi produk, mereka tidak mengalami kesulitan yang berarti, karena ketua karang taruna merupakan chef di salah satu hotel berbintang.

Tidak dapat dipungkiri bahwa usaha yang mereka jalankan merupakan objek pajak dan mereka harus memahami hal tersebut. Jangan sampai ketidaktahuan mereka mengenai perpajakan membuat usaha mereka berhenti di tengah jalan. Berdasarkan hal tersebut maka menurut hemat kami diperlukan adanya penyuluhan mengenai perpajakan bagi UMKM yang diharapkan dapat membuat mereka memahami perpajakan dan mengaplikasikannya dalam kegiatan bisnis mereka.

Dalam proses penyuluhan yang dilaksanakan tersebut akan dilaksanakan oleh tim abdimas Universitas Indraprasta PGRI yang terdiri dari dua orang dosen dan satu orang mahasiswa. Tujuan akhir dari penyuluhan ini adalah membantu pemerintah dalam meningkatkan penerimaan pajak dari sektor UMKM.

\section{METODE PELAKSANAAN}

Metode pelaksaan yang akan dilakukan dalam kegiatan ini adalah melalui beberapa tahap, yaitu observasi langsung, wawancara, dan terakhir melaksanakan penyuluhan. Adapun waktu pelaksanaan yang rencana semula pengabdian masyarakat ini akan dilaksanakan pada April 2020, namun baru dapat dilaksanakan pada 2 Agustus 2020. Dikarenakan pandemik, pelaksanaan pun diadakan melalui media Zoom Meeting.

\section{HASIL DAN PEMBAHASAN}

Hasil evaluasi setelah mengadakan kegiatan penyuluhan dan pelatihan tentang perpajakan bagi UMKM pada Kelompok Karang Taruna Kelurahan Balekambang Jakarta Timur yaitu mereka sangat antusias. Hal ini dibuktikan dengan pertanyaanpertanyaan yang diajukan kepada tutor sangat beragam dan sangat berkaitan erat dengan keinginan untuk memahami peraturan dan perhitungan perpajakan atas UMKM yang mereka miliki. 
Vol. 1, No. 3,

November

2020

pp. 93-99

e-ISSN:

2722-2004

Title

Counseling and Training

on Taxation

for Micro,

Small, and

Medium

Enterprise

(MSME) at

Karang

Taruna

Balekambang

Village, East

Jakarta

Author

Siti Juriah, R. Juniawaty
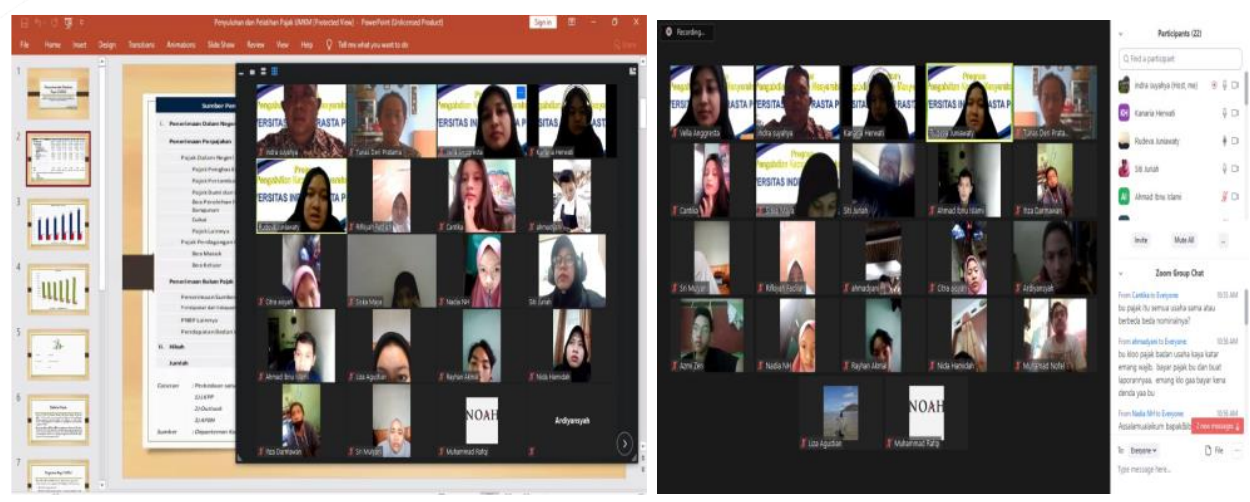

Gambar 2. Para peserta terlihat antusias dalam mengikuti kegiatan penyuluhan

Teori-teori dan praktik yang telah diberikan oleh tutor, diharapkan dapat memberi motivasi bagi para peserta agar ke depannya memahami cara menghitung pajak atas usaha mereka.

Berikut contoh soal yang disampaikan pada saat penyuluhan dan pelatihan Unit Usaha Karang Taruna yang memiliki peredaran bruto selama tahun 2018 dan 2019.

Tabel 1. Peredaran Bruto Tahun 2018

\begin{tabular}{llc}
\hline \multicolumn{1}{c}{ Bulan } & Peredaran Bruto & Peredaran Bruto Kumulatif \\
\hline Januari & Rp. 50.000.000,00 & Rp. 50.000.000,00 \\
Februari & Rp. 53.000.000,00 & Rp. 103.000.000,00 \\
Maret & Rp. 49.000.000,00 & Rp. 152.000.000,00 \\
April & Rp. 62.500.000,00 & Rp. 214.500.000,00 \\
Mei & Rp. 66.000.000,00 & Rp. 280.500.000,00 \\
Juni & Rp. 60.000.000,00 & Rp. 340.500.000,00 \\
Juli & Rp. 57.000.000,00 & Rp. 397.500.000,00 \\
Agustus & Rp. 54.500.000,00 & Rp. 452.000.000,00 \\
September & Rp. 51.000.000,00 & Rp. 503.000.000,00 \\
Oktober & Rp. 47.000.000,00 & Rp. 550.000.000,00 \\
November & Rp. 50.000.000,00 & Rp. 600.000.000,00 \\
Desember & Rp. 60.000.000,00 & Rp. 660.000.000,00 \\
\hline
\end{tabular}

Tabel 2. Peredaran Bruto Tahun 2019

\begin{tabular}{llc}
\hline \multicolumn{1}{c}{ Bulan } & Peredaran Bruto & Peredaran Bruto Kumulatif \\
\hline Januari & Rp. $61.000 .000,00$ & Rp. 61.000.000,00 \\
Februari & Rp. 65.000.000,00 & Rp. 126.000.000,00 \\
Maret & Rp. 69.000.000,00 & Rp. 195.000.000,00 \\
April & Rp. 71.500.000,00 & Rp. 266.500.000,00 \\
Mei & Rp. 75.000.000,00 & Rp. 341.500.000,00 \\
Juni & Rp. 77.000.000,00 & Rp. 418.500.000,00 \\
Juli & Rp. 80.000.000,00 & Rp. 498.500.000,00 \\
Agustus & Rp. 80.500.000,00 & Rp. 597.000.000,00 \\
September & Rp. 87.000.000,00 & Rp. 666.000.000,00 \\
Oktober & Rp. 89.000.000,00 & Rp. 755.000.000,00 \\
November & Rp. 91.000.000,00 & Rp. 846.000.000,00 \\
Desember & Rp. 93.000.000,00 & Rp. 939.000.000,00 \\
\hline
\end{tabular}

Berdasarkan data pada tabel maka dapat kita hitung besaran pajak sebagai berikut: 1. Untuk perhitungan pajak tahun 2018 terbagi menjadi dua tarif :

a. Terhitung Januari sampai dengan Juni 2018, perhitungan pajak mengikuti PP No. 46 Tahun 2013 dengan tarif pajak 1\% dari peredaran bruto. 
b. Terhitung Juli 2018 sampai dengan seterusnya, perhitungan pajak mengikuti PP No. 23 tahun 2018 dengan tarif pajak 0,5\% dari peredaran bruto. Berikut cara menghitung pajak tersebut:

1) Tahun 2018

\begin{tabular}{lccc}
\hline \multicolumn{1}{c}{ Bulan } & Peredaran Bruto & Tarif & PPh Terutang \\
\hline Januari & Rp. 50.000.000,00 & $1 \%$ & Rp. 500.000,00 \\
Februari & Rp. 53.000.000,00 & $1 \%$ & Rp. 530.000,00 \\
Maret & Rp. 49.000.000,00 & $1 \%$ & Rp. 490.000,00 \\
April & Rp. 62.500.000,00 & $1 \%$ & Rp. 625.000,00 \\
Mei & Rp. 66.000.000,00 & $1 \%$ & Rp. 660.000,00 \\
Juni & Rp. 60.000.000,00 & $1 \%$ & Rp. 600.000,00 \\
Juli & Rp. 57.000.000,00 & $0,5 \%$ & Rp. 285.000,00 \\
Agustus & Rp. 54.500.000,00 & $0,5 \%$ & RP. 272.500,00 \\
September & Rp. 51.000.000,00 & $0,5 \%$ & Rp. 255.000,00 \\
Oktober & Rp. 47.000.000,00 & $0,5 \%$ & Rp. 235.000,00 \\
November & Rp. 50.000.000,00 & $0,5 \%$ & Rp. 250.000,00 \\
Desember & Rp. 60.000.000,00 & $0,5 \%$ & Rp. 300.000,00 \\
\hline
\end{tabular}

2) Tahun 2019

\begin{tabular}{|c|c|c|c|c|}
\hline \multirow{13}{*}{ Batas } & Bulan & Peredaran Bruto & Tarif & PPh Terutang \\
\hline & Januari & Rp. 61.000.000,00 & $0,5 \%$ & Rp. $305.000,00$ \\
\hline & Februari & Rp. 65.000.000,00 & $0,5 \%$ & Rp. $325.000,00$ \\
\hline & Maret & Rp. $69.000 .000,00$ & $0,5 \%$ & Rp. $345.000,00$ \\
\hline & April & Rp. 71.500.000,00 & $0,5 \%$ & Rp. $357.500,00$ \\
\hline & Mei & Rp. 75.000.000,00 & $0,5 \%$ & Rp. $375.000,00$ \\
\hline & Juni & Rp. 77.000.000,00 & $0,5 \%$ & Rp. $385.000,00$ \\
\hline & Juli & Rp. 80.000.000,00 & $0,5 \%$ & Rp. $400.000,00$ \\
\hline & Agustus & Rp. 80.500.000,00 & $0,5 \%$ & Rp. $402.500,00$ \\
\hline & September & Rp. 87.000.000,00 & $0,5 \%$ & Rp. $435.000,00$ \\
\hline & Oktober & Rp. 89.000.000,00 & $0,5 \%$ & Rp. $445.000,00$ \\
\hline & November & Rp. $91.000 .000,00$ & $0,5 \%$ & Rp. $455.000,00$ \\
\hline & Desember & Rp. $93.000 .000,00$ & $0,5 \%$ & Rp. $465.000,00$ \\
\hline
\end{tabular}

pembayaran PPh Final tersebut pada tanggal 10 setiap bulannya. Sedangkan pelaporan tidak dilakukan setiap bulan, melainkan dilaporkan pada SPT tahunan.

Yang perlu diingat pada penerapan PP No. 23 tahun 2018 ini adalah perhitungan pajak dihitung dari penghasilan bruto atau peredaran usaha, tanpa melihat apakah usaha tersebut untung atau rugi. PP 23 tahun 2018 dibuat dalam rangka mempermudah Wajib Pajak untuk menghitung utang pajaknya, namun jika pada operasionalnya usaha mengalami kerugian atau bahkan memiliki pajak penghasilan yang dipotong pihak lain, maka pengusaha dapat mengajukan permohonan pada Ditjen Pajak untuk menggunakan pajak uang dikenai PPh Pasal 17 Undang-Undang Nomor 36 Tahun 2008 tentang Pajak Penghasilan.

Diharapkan dengan penyuluhan dan pelatihan terkait dengan usaha berbasis UMKM, remaja karang taruna yang merupakan pelaku usaha baru dapat memahami bahwa dalam usaha yang mereka jalankan terdapat pajak yang harus disetorkan kepada Negara. Hasil lain dari penyuluhan dan pelatihan ini adalah pelaku usaha baru ini, yang semuanya adalah remaja dan banyak yang belum memiliki pengalaman berbisnis, dapat mempertimbangkan usaha yang mereka jalankan tersebut akan dipotong PP 23 atau PPh Pasal 17 UU No. 36 tahun 2008. Diharapkan mereka dapat menimbang-nimbang untung dan rugi dari pemilihan aturan perpajakan yang terkait dengan usaha tersebut. 
Vol. 1, No. 3,

November

2020

pp. 93-99

e-ISSN:

2722-2004

\section{Title}

Counseling and Training

on Taxation

for Micro,

Small, and

Medium

Enterprise

(MSME) at

Karang

Taruna

Balekambang

Village, East

Jakarta

Author

Siti Juriah, R. Juniawaty

\section{SIMPULAN}

Simpulan dari semua kegiatan penyuluhan dan pelatihan yang telah dilaksanakan adalah sebagai berikut:

1. Memiliki kesadaran akan usaha mereka yang merupakan objek perpajakan.

2. Memiliki kemampuan untuk menghitung $P P h$ terutang atas penghasilan usaha mereka.

3. Menghitung untung rugi dari pemilihan penggunaan PP No. 23 tahun 2018 dan PPh Pasal 17 UU No. 36 tahun 2008.

Melaksanakan pengabdian kepada masyarakat merupakan kewajiban bagi para dosen di Indonesia. Untuk ke depannya, diharapkan para dosen bisa melakukan pengabdian kepada masyarakat lebih baik lagi dengan pemberian materi yang lebih beragam dan dapat bermanfaat bagi masyarakat pada umumnya.

\section{DAFTAR PUSTAKA}

Diana, A. \& Setiawati, L. (2010). Cara Mudah Menghitung Pajak Penghasilan Anda. Yogyakarta : Andi Offset

Fitriandi, P. Aryanto, Y. \& Priyono, A. P. (2010). USKP Review Volume 5 : Ujian Sertifikasi Konsultan Pajak. Jakarta: Salemba Empat

Ikatan Akuntan Indonesia. (2016). Modul Pelatihan Pajak Terapan Brevet AB Terpadu. Jakarta: Ikatan Akuntan Indonesia

Juniawaty, R. dkk (2019). Perpajakan untuk Pemula. Jakarta: Unindra Press.

Lubis, I., L. Abidah Sari. (2014). Praktikum Perpajakan All Taxes. Jakarta: Mitra Wacana Media

Mardiasmo. (2016). Perpajakan - Edisi Terbaru 2016. Yogyakarta: Andi Offset

Pohan, C. A. (2014). Pembahasan Komprehensif : Perpajakan Indonesia Teori dan Kasus. Jakarta : Mitra Wacana Media

Pusat Pengembangan Fakultas Ekonomi Universitas Indonesia. (2014). Perpajakan Brevet $A b+e S P T$. Depok: PPA - FEUI

Resmi, S. (2017). Perpajakan: Teori dan Kasus. Jakarta: Salemba Empat

Saptono, P. B. (2016). USKP Review 2017 - Volume A. Cetakan Pertama. Jakarta: Pratama Indomitra

Saptono, P. B. (2017). Buku Pintar Pajak. Cetakan Kedua. Jakarta: Pratama Indomitra.

\section{Situs Online}

Adharsyah, T. (2019). Mengejar Penerimaan Perpajakan Rp 1.819,2 T di 2020, Sanggup? Cnbcindonesia.com. Diakses pada 8 Maret 2020 di https://www.cnbcindonesia.com/news/20190816172700-4-92623/mengejarpenerimaan-perpajakan-rp-18192-t-di-2020-sanggup

Jayani, D. H. \& Widowati, H. (2019). APBN 2020 Disahkan, Ini Postur Anggarannya. Katadata.co.id. Diakses pada 8 Maret 2020 di https://databoks.katadata.co.id/datapublish/2019/09/24/apbn-2020-disahkanini-postur-anggarannya

n.n. (n.d.). Pokok-Pokok APBN 2020 Akselerasi Daya Saing Melalui Inovasi dan Penguatan Kualitas Sumber Daya Manusia. Kemenkeu.go.id. Diakses pada 8 
KANGMAS: Karya Ilmiah Pengabdian Masyarakat, 1 (3), November 2020 - 99

http://journal.neolectura.com/index.php/Kangmas

Maret 2020 di https://www.kemenkeu.go.id/media/13730/informasiapbn-2020.pdf

Sukarno, P. A. (2019) Masih Minim Penerimaan Pajak dari Sektor UMKM. Bisnis.com. Diakses pada 9 Maret 2020 di https://ekonomi.bisnis.com/read/20190502/259/917630/masih-minimpenerimaan-pajak-dari-sektor-umkm

\section{Jurnal}

Damayanti, M., Mahsuni, A. W., \& Afifudin. (2020). Analisis Faktor-Faktor yang Mempengaruhi Kepatuhan Wajib Pajak Orang Pribadi untuk Membayar Pajak dengan Kondisi Keuangan dan Preferensi Risiko Wajib Pajak sebagai Variabel Moderating (Studi Kasus pada Wajib Pajak yang Terdaftar di KPP Pratama Malang Utara). E-jra Vol. 09 No. 03

Juniawaty, R. (2015). Implementasi PP Nomor 46 Tahun 2013 Pada Sektor UMKM di Indonesia. Journal of Applied Business and Economics Volume 2 Nomor 1. https://journal.lppmunindra.ac.id/index.php/JABE/article/view/1455

\section{Peraturan Perundangan}

Peraturan Pemerintah Republik Indonesia Nomor 23 Tahun 2018 Tentang Pajak Penghasilan Atas Penghasilan Dari Usaha Yang Diterima Atau Diperoleh Wajib Pajak Yang Memiliki Peredaran Bruto Tertentu.

Peraturan Pemerintah Republik Indonesia Nomor 46 Tahun 2013 Tentang Pajak Penghasilan Atas Penghasilan Dari Usaha Yang Diterima Atau Diperoleh Wajib Pajak Yang Memiliki Peredaran Bruto Tertentu. 